\title{
IL-27/IL-27RA signaling may modulate inflammation and progression of benign prostatic hyperplasia via suppressing the LPS/TLR4 pathway
}

\author{
Hua-Cheng Lo ${ }^{1,2}$, Dah-Shyong Yu$^{3}$, Hong-Wei Gao ${ }^{4}$, Mong-Hsun Tsai ${ }^{5,6}$, Eric Y. Chuang ${ }^{2,6,7}$ \\ ${ }^{1}$ Division of Urological Surgery, Department of Surgery, Tri-Service General Hospital Songshan Branch, National Defense Medical Center, Taipei; \\ ${ }^{2}$ Graduate Institute of Biomedical Electronics and Bioinformatics, National Taiwan University, Taipei; ${ }^{3}$ Division of Urological Surgery, Department \\ of Surgery, ${ }^{4}$ Department of Pathology, Tri-Service General Hospital, National Defense Medical Center, Taipei; ${ }^{5}$ Institute of Biotechnology, \\ ${ }^{6}$ Bioinformatics and Biostatistics Core, Center of Genomic and Precision Medicine, National Taiwan University, Taipei; ${ }^{7}$ Biomedical Technology and \\ Device Research Laboratories, Industrial Technology Research Institute, Hsinchu \\ Contributions: (I) Conception and design: HC Lo, DS Yu, MH Tsai, EY Chuang; (II) Administrative support: EY Chuang, DS Yu; (III) Provision of \\ study materials or patients: HC Lo; (IV) Collection and assembly of data: HC Lo, MH Tsai; (V) Data analysis and interpretation: HC Lo, MH Tsai, \\ HW Gao, EY Chuang; (VI) Manuscript writing: All authors; (VII) Final approval of manuscript: All authors. \\ Correspondence to: Eric Y. Chuang, Sc.D., EMBA. Professor, Department of Electrical Engineering, Graduate Institute of Biomedical Electronics and \\ Bioinformatics, National Taiwan University, Taipei 106. Email: chuangey@ntu.edu.tw; Mong-Hsun Tsai, PhD. Professor, Institute of Biotechnology, \\ National Taiwan University, Taipei 106. Email: motiont@ntu.edu.tw.
}

Background: Benign prostatic hyperplasia $(\mathrm{BPH})$ is the most common urologic disease affecting aging men. The pathogenesis of BPH is multi-factorial, and chronic inflammation (CI) might be the central mechanism. Interleukin (IL)-27 signaling has been suggested as a modulator in autoimmune and inflammatory conditions. In this study, we used microarray experiments to analyze gene expression and molecular phenotypic associated with BPH progression, with a particular focus on CI and IL-27/IL-27RA signaling, and verified the microarray data in cell biology experiments.

Methods: Thirty BPH patients' specimens and clinical parameters were analyzed. BPH patients were divided into two groups based on the average prostate volume $(41.5 \mathrm{~mL})$ : group $1, \leq 40 \mathrm{~mL}$; and group 2, $>40 \mathrm{~mL}$. Microarray experiments were conducted to identify differentially expressed genes (DEGs) by applying appropriate biostatistics to normalize and analyze the dataset. The candidate gene (IL27RA) was validated by quantitative reverse transcriptase-PCR (qRT-PCR) and immunohistochemistry (IHC). The interaction of IL27RA with genes involved in canonical inflammation-associated pathways was investigated by cell biology experiments.

Results: Eighty-three percent of BPH specimens contained inflammatory infiltrates, and the predominant type was CI. The serum PSA levels and prevalence of CI were higher in group 2. Microarray experiments identified 361 DEGs between these 2 groups. IL27RA was down-regulated and associated with prominent CI in BPH tissues of group 2. Validated by qRT-PCR and IHC, the results showed IL-27RA might modulate CI and progression of BPH. Thus, we investigated the interaction of IL27RA with TLR4, IL6, and IL8, which were involved in inflammation-associated pathways. We found the activation of IL-27RA after IL27 treatment led to phosphorylation of STAT1 and STAT3 in prostate epithelial cells. By comparative treatments with lipopolysaccharide (LPS), IL-27, or combination, we found that IL-27/IL-27RA signaling suppressed the production of inflammatory cytokines, IL-6 and IL-8, induced by LPS/TLR4 pathway.

Conclusions: Our study revealed that down-regulation of IL27RA in prostate tissue was associated with higher prevalence of CI and BPH progression. IL-27/IL-27RA signaling suppressed the LPS/TLR4 pathway. We conclude the IL-27/IL-27RA signaling might modulate CI and provide potential therapeutic strategies to prevent $\mathrm{BPH}$ progression. 
Keywords: Benign prostatic hyperplasia (BPH); chronic inflammation (CI); gene expression; IL-27RA

Submitted Mar 15, 2020. Accepted for publication Jun 28, 2020.

doi: $10.21037 /$ tcr-20-1509

View this article at: http://dx.doi.org/10.21037/tcr-20-1509

\section{Introduction}

Benign prostatic hyperplasia $(\mathrm{BPH})$ is the most common urologic disease affecting aging men. The prevalence of $\mathrm{BPH}$ ranges from $50 \%$ to $75 \%$ among men 50 years of age and older, and up to $80 \%$ among men 70 years of age and older (1). BPH is histologically characterized by hyperplastic processes involving both the glandular and stromal compartments, forming nodules in the periurethral region and transition zone of the prostate, and leads to bladder outlet obstruction with various lower urinary tract symptoms (LUTS). Although symptomatic BPH is not usually life threatening, it can affect patients' quality of life, leading to morbidities and eventually causing a heavy burden on health care systems.

Age and hormones are well known contributing factors to the pathogenesis of BPH (2). However, the underlying molecular and cellular factors associated with $\mathrm{BPH}$ progression and LUTS are not fully understood (3). Many studies have suggested chronic inflammation (CI) could be a central mechanism in the development and progression of BPH (4-6). Several famous, large scale clinical studies, including the Medical Therapy of Prostatic Symptoms (MTOPS) study and the Reduction by Dutasteride of Prostate Cancer Event (REDUCE) trial, indicated that $\mathrm{BPH}$ patients with $\mathrm{CI}$ have been shown to have larger prostate volumes, more severe LUTS, and a higher probability of acute urine retention (AUR) than those without CI (7-9). Therefore, it has been hypothesized that prostatic inflammatory infiltration leads to tissue damage and to a chronic process of wound healing which activates hyperproliferative programs leading to hyperplastic nodules (10-13).

The etiology of chronic prostate inflammation is still unclear. Various potential sources exist for the initial instigating event, including direct infection, urine reflux inducing chemical and physical trauma, dietary factors, and estrogens (14). Among these, infection might be the main event for initiating a misguided immune response in the human prostate (15). König et al. (16) demonstrated pronounced expression of toll-like receptors (TLRs) and induction of immune-mediated inflammatory processes and cytokine secretion, e.g., interleukin (IL)-6, IL-8 and cyclooxygenase-2 (COX-2), in $\mathrm{BPH}$ tissues and prostate cancer $(\mathrm{PCa})$ cells. Several reports also showed that lipopolysaccharide (LPS) stimulation could induce production of nitrite oxide (17), vascular endothelial growth factor and transforming growth factor $\beta 1$ (TGF $\beta 1$ ) (18) in prostate epithelial cells. These findings suggest a key role of prostate epithelial cells in innate immunity, development of CI, tissue remodeling, and growth of BPH. Additionally, many mediators in CI have been investigated in $\mathrm{BPH}$, including various growth factors and cytokines that have been shown to be involved both in the inflammatory process and in the interactions between epithelial and stromal prostate cells (5). These mediators are released by prostate cells and inflammatory cells (such as T lymphocytes) that can be found in most surgery-derived BPH specimens (19). Moreover, inflammatory mediators may contribute to growth of both prostate epithelial and stromal cells directly through cytokines that stimulate the production of prostate growth factors and indirectly through decreases in prostate cell death via down-regulation of apoptosis $(20,21)$.

IL-27 is a heterodimeric cytokine composed of the subunit protein IL-27p28 and Epstein Bar virus-induced gene 3 (EBI3) (22). IL-27 binds to a heterodimeric receptor complex, which is composed of a ligand-binding chain, IL-27 receptor, $\alpha$ subunit (IL-27RA, also known as WSX1 or TCCR), and an additional signal-transducing chain, gp130 (23). IL-27 activates Janus kinase (JAK) and signal transducer and activator of transcription 1 (STAT1) and STAT3, which modulate the differentiation of $\mathrm{T}$ help cell $(\mathrm{Th})$ types through the activities of downstream transcription factors, such as T-bet (Th1) (24), GATA3 (Th2) (25) and retinoic acid receptor-related orphan receptor $\gamma \mathrm{t}$ (Th17) (26), leading to commitment of Th1 differentiation, Th2/Th17 suppression and IL-10 induction. Through these mechanisms, IL-27 signaling plays an immunosuppressive role and suppresses production of proinflammatory cytokines $(27,28)$. To date, the antiinflammatory properties of IL-27 have only been described in T cells, and so the effect of IL-27 signaling on prostate 
epithelium is unclear.

The distribution of the IL-27 receptor is not restricted to immune cells; it is also expressed in endothelial cells, keratinocytes, and in mammary, lung, and prostate epithelium (23). Recent studies have reported the role of IL-27 in PCa, where it was shown to reduce invasive potential in vitro, including cell viability and migration (29), and to reduce proliferation and vascularization in xenograft tumors (30). Moreover, in human prostate tissues, IL-27RA was found to be expressed by normal epithelia and low grade $\mathrm{PCa}$, but not in tumors of high grade or advanced stage (30). Collectively, these findings suggest that IL-27 signaling might directly suppress $\mathrm{PCa}$ growth in vitro and in vivo. However, the role of IL-27/IL-27RA signaling in CI and $\mathrm{BPH}$ progression is still unclear.

Considering the importance of CI in the development and progression of $\mathrm{BPH}$, we tried to find potential biomarkers/genes associated with prostatic inflammation and growth through gene expression analysis, and to validate them. We first collected prostate tissues from $\mathrm{BPH}$ patients, and characterized their inflammatory status and clinical parameters. Then, we conducted a genome-wide microarray analysis of $\mathrm{BPH}$ tissues and compared gene expression profiles in subgroups of patients with different prostate volumes (group 1, $\leq 40 \mathrm{~mL}$; group 2, >40 mL). $I L 27 R A$ was significantly down-regulated in group 2 compared with group 1 . The expression of IL27RA in prostate tissue was validated by quantitative reverse transcriptase-PCR (qRT-PCR) and immunohistochemistry (IHC). Thus, we hypothesized that IL27RA might play a role in modulating prostatic inflammation and $\mathrm{BPH}$ progression. Furthermore, based on pathway analysis, we performed cell biology experiments to validate IL27RA and its interaction with several genes including TLR4, IL6, and IL8, which were simultaneously up-regulated in canonical pathways associated with immune/inflammatory responses. The cell biology experiments suggested that IL-27/IL27RA signaling might play the role of immune regulator in prostate epithelial cells, and offer a novel therapeutic strategy for attenuating prostatic CI and halting progression of BPH.

\section{Methods}

Collection of patients' data and samples, etbics statement, and grouping

Thirty prostate specimens were obtained from patients who underwent the transurethral resection of the prostate (TURP) and transrectal ultrasound (TRUS)-guided needle biopsy of the prostate at the Division of Urologic Surgery, Department of Surgery, Songshan Branch of Tri-Service General Hospital (TSGH) from 2007 to 2009. The tissue samples from prostate biopsies were consistently taken from the transitional zones (TZ) area after suspicious malignancy (either in TZ or peripheral zones) were excluded preliminarily by TRUS. Histological diagnosis of $\mathrm{BPH}$ was confirmed by an independent pathologist. Either the specimens from TURP or biopsy, the patients whose pathologic reports showed cancerous or precancerous lesions were excluded from this study. Prostate tissue specimens were immediately immersed in RNAlater buffer (Applied Biosystems), snap-frozen in liquid $\mathrm{N}_{2}$, and stored at $-80{ }^{\circ} \mathrm{C}$ for RNA extraction. The study was conducted in accordance with the Declaration of Helsinki (as revised in 2013). The study was approved by the Institutional Review Board of TSGH (TSGHIRB Approval Number: 09605-177) and an informed consent was taken from all the patients. BPH patients were divided into two groups based on the average $\mathrm{BPH}$ volume $(41.5 \mathrm{~mL})$ : group 1 , prostate volume $\leq 40 \mathrm{~mL}$; and group 2, prostate volume $>40 \mathrm{~mL}$.

\section{Isolation and labeling of total RNA for gene expression profiling}

Total RNA from the tissue specimens was isolated using TRIzol reagent (Invitrogen) and purified with an RNeasy mini kit (Qiagen) according to the manufacturers' instructions. Labeled cRNA was synthesized using purified total RNA (1-15 $\mu \mathrm{g})$ as a template following Illumina's standard synthesis protocols. HumanRef-8 v2 Expression BeadChip 2.0 arrays (Illumina, Inc.) were hybridized to the biotinylated cRNA targets. After 16 hours of hybridization at $45{ }^{\circ} \mathrm{C}$, the arrays were washed by a Fluidics Station 450 and scanned by a GeneChip Scanner 3000 .

\section{Data mining and pathway analysis}

After scanning, the intensity data from the GeneChip were analyzed by Partek Software (Partek Genomics Suite, RRID:SCR_011860, Partek Inc., St. Louis, MO, USA) for mRNA expression levels. We used the Partek Software to conduct robust multi-array average analysis, which contains background correction, quantile normalization, probe level intensity calculation, and significant gene identification. After data processed, Partek Software was also used to 
conduct principal component analysis (PCA), which reduces higher-dimensional data into a three-dimensional graph, and to evaluate the similarity of gene expression profiles for different samples. Then we used the Genesis program (RRID:SCR_015775), which is a platform to simultaneously visualize and analyze a whole set of gene expression data, to perform hierarchical clustering (HC) analysis and generate a visual representation (heatmap) of the expression profiles. Finally, Ingenuity Pathway Analysis (IPA, RRID:SCR_008653) was applied to describe gene-gene interaction networks, biological functions, and canonical pathways of differentially expressed genes.

\section{Quantitative reverse transcriptase-PCR}

After reverse transcription of $1 \mu \mathrm{g}$ total RNA, real-time PCR was performed by ABI 7300 (Applied Biosystems) with SYBR Green (Sigma) according to standard protocols. The PCR primers were as follows: forward primer IL27RA, 5'-TGCAGGTGAGCTACAAAGTCTGGT-3', reverse primer IL27RA, 5'-AGCAGACCAAAGAGAGGTTGGTGA-3' . Each measurement was made in triplicate and normalized to an 18s RNA (forward primer, 5'-TCAACTTT CGATGATGGTAGTCGCC-3', reverse primer, 5'-TCCTTGGATGTGGTAGCCGTTT-3') control to ensure comparable amounts of cDNA in all wells.

\section{Immunobistochemical staining}

Tissue sections (4- $\mu \mathrm{m}$ thick) were constructed from paraffin-embedded tissues and used for immunostaining. The tissue sections were deparaffinized in xylene and rehydrated in graded alcohol solutions. The tissue sections were then boiled in citrate buffer $(\mathrm{pH} 9)$ for $10 \mathrm{~min}$ and treated with $3 \%$ hydrogen peroxidase to block endogenous peroxidase activity. After washing in phosphate-buffered saline, the tissue sections were incubated with normal goat serum (dilution 1:500; Dako) for $30 \mathrm{~min}$ and incubated with IL-27RA antibody (dilution 1:50; Novus) overnight at $4^{\circ} \mathrm{C}$. Then biotin- and streptavidin-labeled antibodies were used for 3,3'-diaminobenzidine (DAB) staining. Prostate epithelial cells showing cytoplasmic immunoreactivity to IL-27RA antibody were scored as having positive IL-27RA expression.

\section{Chemicals and antibodies}

Lipopolysaccharide (LPS; from Escherichia coli 0127:B8) was purchased from Sigma-Aldrich. Recombinant human cytokine IL-27 was purchased from R\&D Systems. Antibody against IL-27RA (Novus Cat\# NBP1-02708, RRID:AB_2125066) was purchased from Novus. Antiphospho-STAT1(Y701) (Cell Signaling Technology Cat\# 9171, RRID:AB_331591), anti-phospho-STAT3(Y705) (Cell Signaling Technology Cat\# 4113, RRID:AB_2198588), anti-STAT1 (Cell Signaling Technology Cat\# 9172, RRID:AB_2198300), and anti-STAT3 (Cell Signaling Technology Cat\# 9132, RRID:AB_331588) antibodies were purchased from Cell Signaling Technology. AntiTLR4 (Abcam Cat\# ab13556, RRID:AB_300457), antiIL-6 (Abcam Cat\# 1457-1, RRID:AB_562150), and antiIL-8 (Abcam Cat\# ab34100, RRID:AB_775629) antibodies were purchased from $A b c a m$. Beta $(\beta)$-actin (Millipore Cat\# MABT825, RRID:AB_2571580) and horseradish peroxidase linked anti-rabbit (Millipore Cat\# AP307P, RRID:AB_92641), anti-mouse (Millipore Cat\# AP308P, RRID:AB_92635) and anti-goat (Millipore Cat\# AP106P, RRID:AB_92411) secondary antibodies were purchased from Millipore. Secondary antibodies for IHC were from Dako.

\section{Cell culture and treatment}

Human PCa derived epithelial cell lines PC-3 (BCRC, Cat\# 60122, RRID:CVCL_0035), DU-145 (BCRC, Cat\# 60348, RRID:CVCL_0105), and LNCaP (BCRC, Cat\# 60088, RRID:CVCL_1379) were obtained from the Bioresource Collection and Research Center (Hsinchu, Taiwan). The BPH epithelial cell line BPH-1 was a kind gift provided by Simon W. Hayward (Vanderbilt University Medical Center, Nashville, TN, USA). Normal human prostate stroma cell line WPMY-1 (ATCC, Cat\# CRL2854, RRID:CVCL_3814) and normal epithelial cell line RWPE-1(ATCC, Cat\# CRL-11609, RRID:CVCL_3791) were purchased from the American Type Cell Collection. WPMY-1 cells were grown in Roswell Park Memorial Institute (RPMI) medium containing $100 \mathrm{IU} / \mathrm{mL}$ penicillin, $100 \mu \mathrm{g} / \mathrm{mL}$ streptomycin and $10 \%$ fetal bovine serum (Invitrogen) in a humidified $5 \% \mathrm{CO}_{2}$ atmosphere at $37^{\circ} \mathrm{C}$, whereas RWPE- 1 cells were cultured in keratinocyteserum free medium supplemented with recombinant human epidermal growth factor and bovine pituitary extract.

The effect of IL-27 signaling on BPH-1 and PC-3 cells was evaluated. The cells were treated with IL-27 at various concentrations $(0,50,100 \mathrm{ng} / \mathrm{mL})$ and incubated for $30 \mathrm{~min}$ (dose-response assay). For the time-response assay, the cells were treated with $100 \mathrm{ng} / \mathrm{mL}$ of IL-27 for different 
times: 0, 30, and 60min. Stimulated and non-stimulated cells from those cultures were used to observe the total and phosphorylated status of STAT1 and STAT3, respectively.

To determine the response to LPS stimulation on prostate cell lines, the BPH-1 and PC-3 cells were treated with LPS $(10 \mu \mathrm{g} / \mathrm{mL})(17,18)$ and incubated for different times: $0,3,6,12$, and $24 \mathrm{~h}$. Stimulated and non-stimulated cells as well as supernatants from those cultures were collected in different experiments.

To determine the effects of IL-27 signaling on activation of the TLR4 pathway induced by LPS, BPH-1 and PC-3 cells were incubated with $100 \mathrm{ng} / \mathrm{mL}$ IL-27 at least $30 \mathrm{~min}$ before LPS $10(\mu \mathrm{g} / \mathrm{mL})$ was added and further incubated for $6 \mathrm{~h}$. Non-stimulated cells were also treated with IL27 at the same concentrations as the LPS-stimulated cells. Stimulated and non-stimulated cells and supernatants from the cell cultures were collected for the analyses described below.

\section{Western blotting}

Fifty to one hundred $\mu \mathrm{g}$ of total cellular protein were separated by $10 \%$ SDS-PAGE and transferred to Immobilon polyvinyldifluoride membranes. The membrane was blotted with the primary antibody overnight at $4{ }^{\circ} \mathrm{C}$ and with the appropriate secondary antibody for $1 \mathrm{~h}$ at room temperature the next day. Visualization was performed by enhanced chemiluminescence (Millipore) using a UVP BioSpectrum AC Imaging System. To semiquantitate and compare the protein levels, the gels were photographed and the intensities of the bands were analyzed using Image J software (ImageJ, RRID:SCR_003070). The relative band intensities in each reaction were normalized to the mean intensity of the $\beta$-actin band.

\section{Enzyme-linked immunosorbent assay (ELISA) analysis}

Supernatants were collected and centrifuged at 12,000xg for $15 \mathrm{~min}$ to remove cellular debris. A commercial ELISA reaction kit (eBioscience) for IL-6 and IL-8 release from cell supernatants was used according to the manufacturer's protocol.

\section{Statistical analysis}

Clinical parameters were compared between the prostate sample groups which were divided by mean prostate volume. A $\chi^{2}$ test was used to compare qualitative data between the groups. For comparison of quantitative data, a
Mann-Whitney test was used.

We used $t$-test method to reveal target genes. According to mean values, the gene probes whose "fold change" value showed at least $>1.4$ or $<-1.4$ expression difference were enrolled into study. To ensure high reliability of the fold change values obtained from the probes, we set the "false discovery rate" (FDR) $<25 \%$, and the FDR corrected $\mathrm{P}<0.05$ were considered significant. The FDR was determined by using the Benjamini-Hochberg multiple testing procedure.

In cell biological experiments, all data were representative of more than three independent experiments, with each performed in triplicate. Levels of significance between samples were determined by the Student's $t$-test. A value of $\mathrm{P}<0.05$ was considered statistically significant.

\section{Results}

\section{Clinical characteristics of BPH patients}

Patient characteristics are presented in Table 1. The mean age of $\mathrm{BPH}$ patients enrolled in this study was $73.4 \pm 9.9$ years. Tissue samples were obtained from 5 patients with elevated PSA via TRUS-guided needle biopsy, and 25 patients with or without elevated PSA underwent TURP for symptomatic BPH. The mean prostate volume measured by TRUS was $41.5 \pm 21.1 \mathrm{~mL}$ (range 12 to $85 \mathrm{~mL}$ ). The average serum PSA level was $13.2 \mathrm{ng} / \mathrm{mL}$ (range 1.3 to $46.5 \mathrm{ng} / \mathrm{mL}$ ). Most of the specimens revealed inflammatory infiltration (83.3\%), and of these, the percentages of acute, chronic, and mixed acute and chronic inflammation were $8 \%, 64 \%$ and $28 \%$, respectively. BPH patients were divided into two groups based on prostate volume as described in the Methods. Several clinical parameters were compared between these 2 groups. The preoperative prostate volume and PSA level were significant between them, whereas the IPSS, maximal uroflow rate, post void residual volume, and surgery type were insignificant. The prevalence of inflammation in each group was similar and showed no statistical difference $(85.7 \%$ $v s .81 .3 \%)$. However, the serum PSA levels and prevalence of CI were significantly higher in group 2 compared with group 1 (PSA: 15.8 vs. 10.5; CI: $62.5 \%$ vs. $42.8 \%$ ). These data suggest that CI is positively correlated with PSA level and prostate volume, as well as $\mathrm{BPH}$ progression.

\section{Gene expression profiling in $\mathrm{BPH}$ tissues}

Of the 30 patients, 23 samples (10 from group 1 and 13 
Table 1 Patients' demography and comparison of clinical parameters and histological characteristics

\begin{tabular}{|c|c|c|c|c|}
\hline & All patients $(n=30)$ & Group $1(n=14)$ & Group $2(n=16)$ & $\begin{array}{c}\text { Statistical } \\
\text { Analysis, } \mathrm{P} \text { value }\end{array}$ \\
\hline $\begin{array}{l}\text { Average age (SD) (range, } \\
\text { median, IQR) }\end{array}$ & $73.4(9.9)(47-88,75.5,13)$ & $76.2(9.4)(47-81,78,6)$ & 70.6 (9.9) $(57-88,72,18)$ & $\begin{array}{c}\text { Mann-Whitney, } \\
0.089\end{array}$ \\
\hline $\begin{array}{l}\text { Average preoperative prostate } \\
\text { volume }(\mathrm{mL})(\mathrm{SD}) \text { (range, } \\
\text { median, IQR) }\end{array}$ & $41.5(21.1)(12-85,40,30)$ & $22.2(11.7)(12-40,20,23.1)$ & $55.8(15.3)(41.8-85,50,30.2)$ & $\begin{array}{l}\text { Mann-Whitney, } \\
<0.01\end{array}$ \\
\hline $\begin{array}{l}\text { Average preoperative IPSS } \\
\text { (SD) (range, median, IQR) }\end{array}$ & $28.6(6.5)(13-35,30.5,5)$ & $29.1(6.4)(13-35,30.5,5)$ & $28.1(6.8)(14-35,30.5,5)$ & $\begin{array}{l}\text { Mann-Whitney, } \\
0.674\end{array}$ \\
\hline Surgery type: biopsy/TURP & $5 / 25$ & $2 / 12$ & $3 / 13$ & $\chi^{2}$ test, 0.743 \\
\hline $\begin{array}{l}\text { Inflammation (presence/ } \\
\text { absence) (acute/chronic/ } \\
\text { mixed/absence) }\end{array}$ & $83.3 \%(25 / 5)(2 / 16 / 7 / 5)$ & $85.7 \%(12 / 2)(0 / 6 / 6 / 2)$ & $81.3 \%(13 / 3)(2 / 10 / 1 / 3)$ & $\chi^{2}$ test, 0.743 \\
\hline $\begin{array}{l}\text { IL-27RA staining positive: } \\
\text { negative (\% of positive stain) }\end{array}$ & 11: $19(36.6 \%)$ & 8: $6(57.1 \%)$ & 3: $13(18.7 \%)$ & $\chi^{2}$ test, $<0.05$ \\
\hline
\end{tabular}

$\mathrm{SD}$, standard deviation; IQR, interquartile range; PSA, prostatic specific antigen; IPSS, international prostate symptom score; Qmax, maximal uroflow rate; TURP, transurethral resection of prostate; IL-27RA, interleukin-27 receptor, alpha subunit.

from group 2) with good RNA quality were subjected to microarray experiments. The gene expression of $\mathrm{BPH}$ tissue in group 1 versus group 2 was analyzed using the highthroughput whole genome BeadChip arrays. We found 361 differentially expressed genes with a fold change of $>1.4$ or $<-1.4$. Among them, 214 genes $(59.2 \%)$ were downregulated and 147 genes (40.8\%) were up-regulated in $\mathrm{BPH}$ tissue of group 2 compared with group 1. PCA was used to examine whether the differentially expressed genes could be used to distinguish larger volume from smaller volume $\mathrm{BPH}$ tissues. The results of PCA showed that larger volume (group 2) BPH tissues aggregated to the upper right side, whereas smaller volume (group 1) BPH tissues clustered to the lower left, indicating that the differentially expressed genes could be used to separate the tissue samples into two distinct groups (Figure 1A). HC analysis showed different patterns of gene expression between the 2 groups of $\mathrm{BPH}$ patients (Figure 1B).

\section{Differential expression of immune-inflammation signaling pathways between two groups of BPH patients}

To investigate which genetic networks and canonical pathways were significantly changed in group 2 compared with group 1, IPA was performed. The functions of "Protein Synthesis, Gene Expression, RNA Trafficking", "Cell Cycle, Cellular Assembly and Organization, DNA Replication, Recombination, and Repair", and "Cell Signaling, Gene Expression, Cell Cycle" were identified as the major functions of the top three genetic networks (Table S1). We also identified 10 canonical pathways that were significantly $[-\log (\mathrm{P})>4.27]$ enriched in larger volume BPH tissues (Table S2). The top three pathways with the most significant $\mathrm{P}$ value were "Triggering receptor expressed on myeloid cells 1" (TREM1) signaling, "Liver $\mathrm{X}$ receptor/retinoid X receptor" (LXR/RXR) signaling, and "Communication between innate and adaptive immune cells". Upon Inspection of genes listed in the 
A

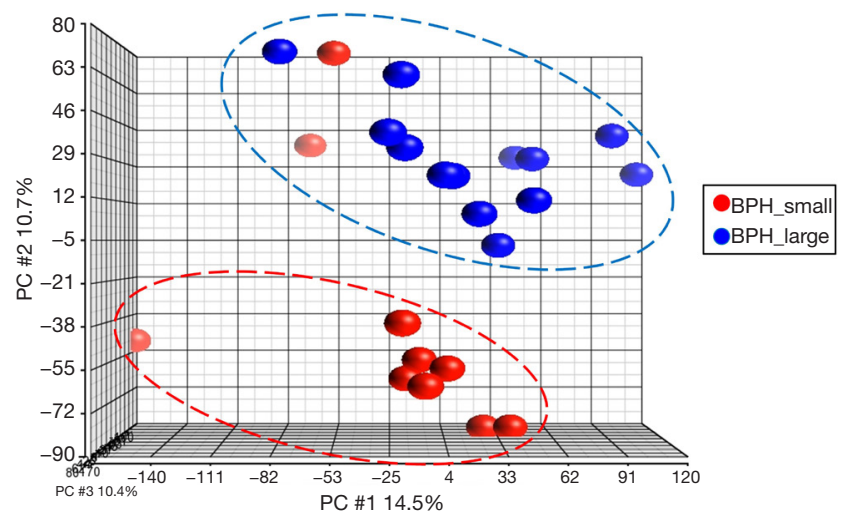

C

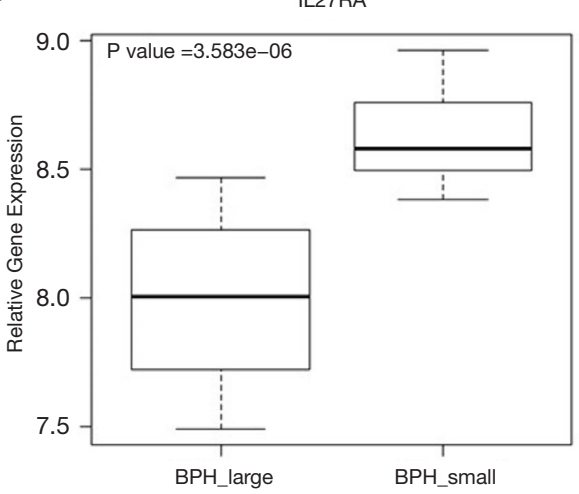

B

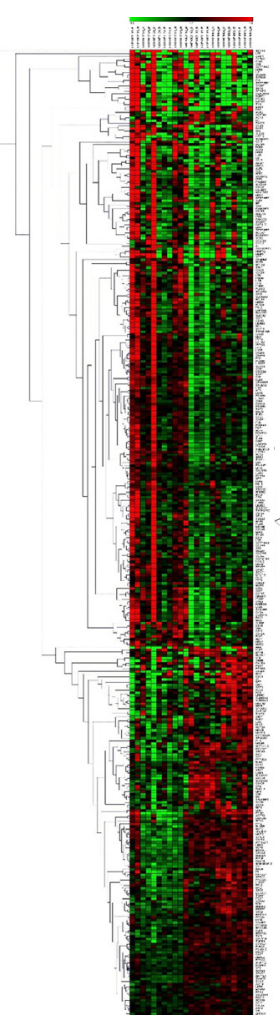

Heatmap

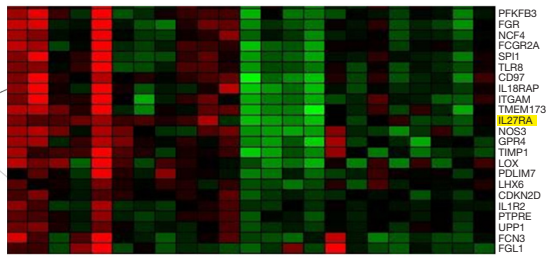

Figure 1 Microarray analysis of gene expression in benign prostatic hyperplasia (BPH) tissues. (A) Principal component analysis of the BPH samples ( $\mathrm{n}=23$ ). Red dots denote small volume BPH tissues; blue dots denote large volume BPH tissues. Each dot represents the expression values of the significant genes that were summarized on the first two principal component coordinates. (B) Hierarchical clustering of the 361 significantly different genes. Input data are the $\log 2$ ratios of large BPH intensity over small BPH intensity. Red indicates genes that were upregulated in BPH tissues; green indicates down-regulated genes. The data are organized by prostate size: labels of small samples are in black ( $\mathrm{n}=10$, left side) and those of large samples in orange/gold ( $\mathrm{n}=13$, right side). (C) A box plot shows the relative expression of $I L 27 R A$ between large and small volume BPH tissues by quantitative reverse transcriptase-PCR (qRT-PCR). 18s RNA was used for an internal control.

above pathways, we identified several genes that were upregulated simultaneously, including IL6, TLR4, and IL8 (Figure S1), which might participate in promoting prostatic inflammation and progression of $\mathrm{BPH}$.

\section{Down-regulation of IL27RA in BPH tissue of group 2}

The IPA showed that the pathways associated with immune/ inflammation regulation were significantly different between two groups of BPH patients. To identify potential biomarkers or candidate genes involved in CI that might lead to BPH, we focused on genes associated with immune/ inflammation response and modulation, and found that
$I L 27 R A$ was significantly down-regulated in group 2. To validate the results of the microarray analysis, qRT-PCR was conducted in each of the $30 \mathrm{BPH}$ specimens. As shown in Figure 1C, qRT-PCR results were consistent with the microarray data, and $I L-27 R A$ expression was significantly $(\mathrm{P}=3.583 \mathrm{E}-06)$ down-regulated in group 2. Additionally, IHC stains were used to validate the expression of IL27RA in BPH tissue. Positive expression of IL-27RA was defined as being immunoreactive to IL-27RA antibody in the glandular epithelial cells of prostate tissue (Figure $2 A$ ). The results showed less positive expression of IL-27RA in group 2 compared with group 1 (18.7\% vs. 57.1\%; $\mathrm{P}<0.05$, Table 1), suggesting that less expression of IL-27RA in $\mathrm{BPH}$ 
epithelium might be associated with more CI and increased progression of $\mathrm{BPH}$.

\section{Constitutive expression of IL-27RA and TLR4 in buman prostate cells}

Motivated by the above results showing that several genes involved in immune/inflammation associated canonical pathways were simultaneously up-regulated, while the expression of IL27RA was significantly down-regulated in group 2, we hypothesized that IL27RA might modulate $\mathrm{CI}$ and $\mathrm{BPH}$ progression via regulating the known TLR4 pathway and its downstream products, IL6 and IL8 (16). Western blotting was performed to verify the presence of IL-27RA and TLR4 in prostate cell lines, and as shown in Figure 2, IL-27RA and TLR4 were differentially expressed in epithelial cells (RWPE-1, BPH-1, PC-3, DU-145) and in stroma cells (WPMY-1). The expression of IL-27RA was highest in RWPE-1, BPH-1 and PC-3 cells (Figure 2B), while TLR4 expression was highest in BPH-1, DU-145, and PC-3 cells (Figure 2C). The higher level of TLR4 expression in hyperplastic BPH-1 cells and in PCa-derived DU-145 and PC-3 cells in comparison to the normal epithelial cells, RWPE-1, suggests that the TLR4 pathway might play a connecting role between inflammation and prostate cell proliferation in $\mathrm{BPH}$ or carcinogenesis in PCa.

\section{LPS-induced IL-6 and IL-8 expression in BPH-1 and $P C-3$ cells}

The fact that TLR4 is constitutively expressed in prostate epithelial cells indicates that either microbial or endogenous materials could trigger inflammatory responses in these cells (16). Given the findings above from microarray and western blot analyses, we hypothesized that TLR4 signaling could induce production of proinflammatory cytokines, IL-6 and IL-8, in BPH-1 and PC-3 cells by LPS stimulation. Thus, a time-course study was conducted, and western blotting and ELISA were used to characterize the expression levels of IL-6 and IL-8 at 0, 3, 6, 12, and $24 \mathrm{~h}$ after LPS exposure. In BPH-1 cells, we found that IL-6 was significantly increased at $6 \mathrm{~h}$ after LPS stimulation in western blotting (Figure $3 A$ ) and ELISA (Figure 3B), whereas IL-8 was progressively elevated with time in the ELISA, but undetectable in western blotting. In contrast, the levels of IL-6 and IL-8 followed the same pattern of expression over time upon LPS stimulation in PC-3 cells, reaching a peak at $6 \mathrm{~h}$ in both western blotting (Figure $3 C$ ) and ELISA analyses (Figure 3D). These results showed that both BPH-1 and PC-3 cells can activate innate immunity and initiate an inflammatory response to LPS by inducing production of IL-6 and IL-8 in a time-dependent manner.

\section{Suppression of LPS-induced IL-6 and IL-8 expression by IL-27}

The induction of IL-6 and IL-8 in prostate tissues has been shown to be not only associated with the inflammatory response in $\mathrm{BPH}$, but involved in proliferation, malignant transformation, and migration in PCa (31,32). Our data have shown the presence of IL-27RA and of IL-27/IL27RA signaling. However, the functions of IL-27/IL-27RA signaling in prostate epithelial cells have not been studied. Thus, we used conditional treatment to investigate the effects of IL-27 signaling on LPS-induced expression of IL-6 and IL-8 in BPH-1 and PC-3 cells. Each prostate cell line was treated with either LPS $(10 \mu \mathrm{g} / \mathrm{mL})$ only, IL-27 (50 ng/mL) only, or combined LPS $(10 \mu \mathrm{g} / \mathrm{mL})$ and IL27 (50 ng/mL). In BPH-1 cells, we found that treatment with IL-27 suppressed on LPS-induced expression of both IL-6 and IL-8 (Figure 4A,B). IL-27 treatment alone had insubstantial effects on the expression of IL-6 and IL-8. Similar results were observed in PC-3 cells (Figure 4C,D). Collectively, our findings suggest that IL-27/IL-27RA signaling can suppress the expression of inflammatory cytokines, IL-6 and IL-8, induced by LPS stimulation.

\section{Activation of IL-27/IL-27RA signaling leads to phosphorylation of STAT1 and STAT3}

We have showed that there is constitutive expression of IL-27RA in prostate cells (Figure $2 \mathrm{~B}$ ), but the role and mechanism of IL-27/IL-27RA signaling in BPH-1 and PC-3 cells is still unclear. IL-27 has been described in lymphocytes to activate both the STAT1 and STAT3 pathways (33). By western blotting, we found that phosphorylation of STAT1 and STAT3 were increased in BPH-1 and PC-3 cells by IL-27 stimulation in a dosedependent manner (Figure 5, right panels). In time-response experiments, the phosphorylation of STAT1 and STAT3 were found to be induced at 30 and $60 \mathrm{~min}$ after IL-27 stimulation (Figure 5, left panels). These results showed that IL-27RA signaling in BPH-1 and PC-3 cells leads to phosphorylation of STAT1 and STAT3 after IL-27 stimulation. 
A

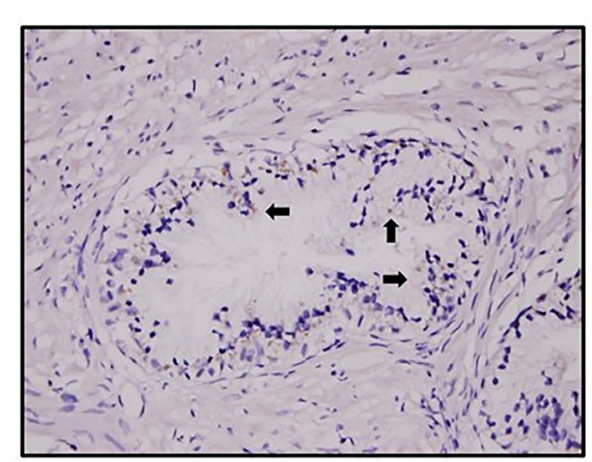

IL-27RA (-)

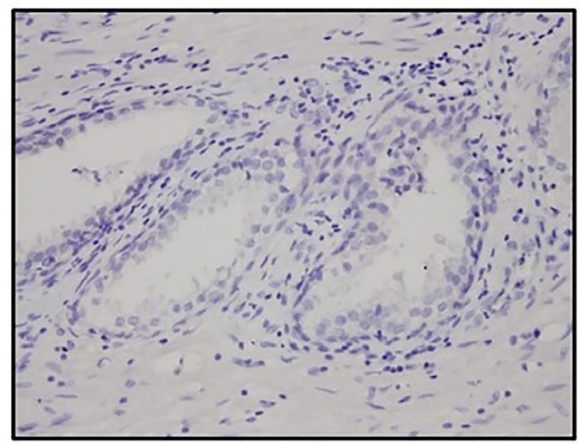

B

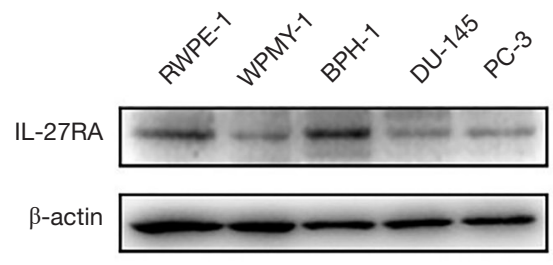

IL-27RA

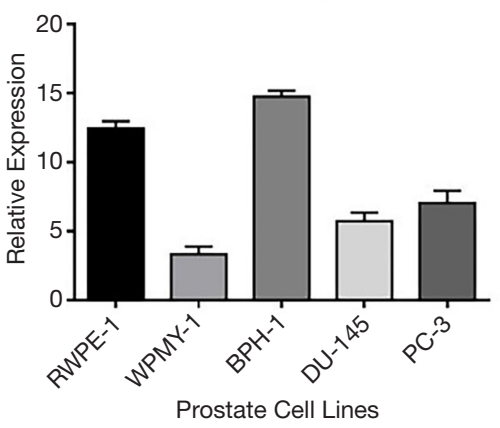

TLR4
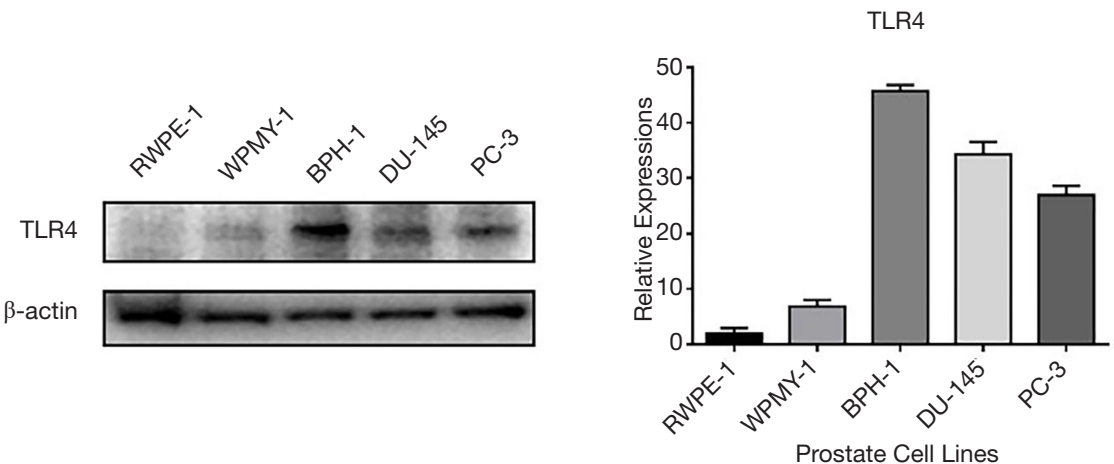

Figure 2 Immunohistochemical validation of Interleukin-27 receptor, $\alpha$ subunit (IL-27RA) expression in BPH specimens and relative expression of toll-like receptor 4 (TLR4) and IL-27RA in the human prostate cell lines. (A) Representative images of immunohistochemical staining for IL-27RA protein on primary specimens from BPH patients. Patients were divided into the positive IL-27RA group (left) or the negative IL-27RA group (right), with sections of nodular gland showing immunoreactivity to IL-27RA antibody (arrow) on the surface of prostate epithelial cells (original magnification: 200x). The relative expression of IL-27RA (B) and TLR4 (C) was determined by western blotting in prostate cell lines RWPE-1, WPMY-1, BPH-1, DU-145, and PC-3. Data was representative of more than three independent experiments, with each performed in triplicate. Semi-quantitation was done by densitometry using ImageJ software. 
A

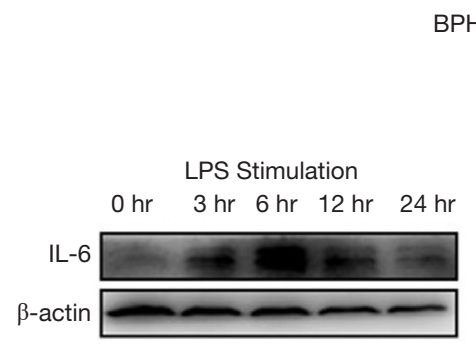

$\mathrm{BPH}-1$

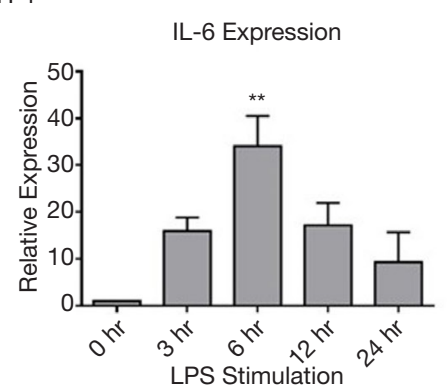

C

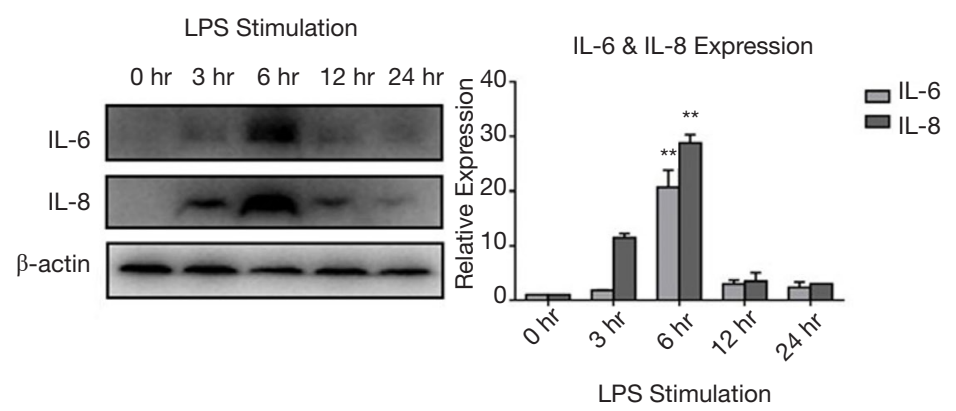

B

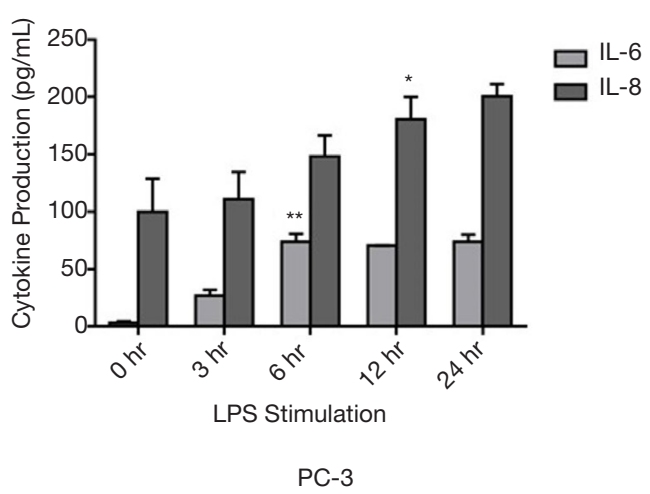

Figure 3 The relative expression of proinflammatory cytokines, interleukin 6 (IL-6) and IL-8, in BPH-1 and PC-3 prostatic cells after Lipopolysaccharide (LPS) stimulation. BPH-1 and PC-3 cells were treated with LPS (10 $\mu \mathrm{g} / \mathrm{mL})$ for $0,6,12$, and 24 h, and then cellular proteins and cell-free culture supernatants were collected for western blotting and ELISA analysis, respectively. The relative expression of IL-6 and IL-8 in BPH-1 cells after LPS stimulation at different time points was determined by western blotting (A) and enzyme-linked immunosorbent assay (ELISA) analysis (B). The western blotting showed the expression of IL-8 was absent in BPH-1 cells. The relative expression of IL-6 and IL-8 in PC-3 cells after LPS stimulation at different time points was measured by western blotting (C) and ELISA analysis (D). Semi-quantitation of western blotting was done by densitometry using ImageJ software. Data was representative of more than three independent experiments, with each performed in triplicate. ${ }^{*} \mathrm{P}<0.05,{ }^{* *} \mathrm{P}<0.001$.

\section{Discussion}

To our knowledge, this is the first study of its kind to specifically investigate gene expression focusing on CI and $\mathrm{BPH}$ progression. We first assessed the characteristics of a group of Taiwanese $\mathrm{BPH}$ patients, and analyzed the prevalence and patterns of inflammation in their specimens. These specimens were characterized by indicators of CI. Microarray experiments identified IL27RA as a potential genetic biomarker significantly down-regulated in BPH. In vitro experiments were performed to investigate IL-27/IL27RA signaling and its interaction with several genes, such as TLR4, IL6, and IL8, which were identified from IPA. Our results showed that IL-27/IL-27RA signaling could modulate the inflammatory response induced by LPS/ TLR4 signaling in BPH-1 and PC-3 cells. Collectively, these data support a novel role of IL-27/IL-27RA signaling in modulating $\mathrm{CI}$ and progression of $\mathrm{BPH}$.

In our clinical data (Table 1), we found that prostatic inflammation was widely distributed in BPH specimens, and that among subtypes of inflammation, CI positively correlated with BPH volume. Although the role of CI in BPH pathogenesis is still unclear, several studies have provided supportive evidences. These studies concluded that patients with prostatic inflammation were more likely to progress clinically in terms of worse symptoms, AUR or BPH related surgery $(8,9)$. A significant association among the degree of prostatic inflammation, prostate volume, and serum PSA levels was confirmed $(7,19)$. Consistently, we found that there were higher serum PSA levels and a higher percentage of $\mathrm{CI}$ in larger volume prostate tissues compared 
A

$\mathrm{BPH}-1$
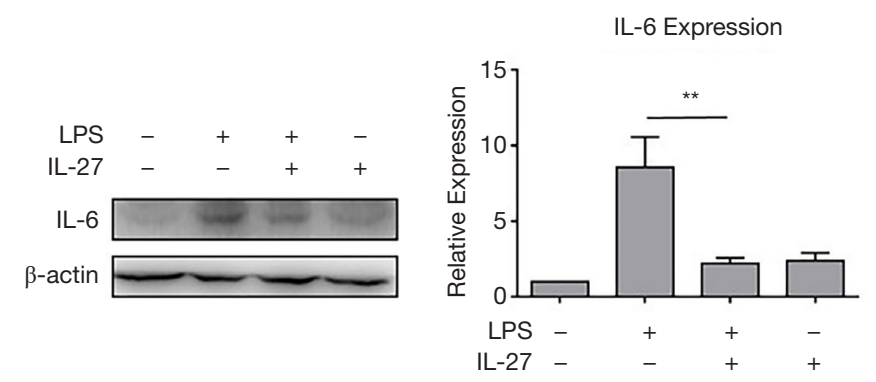

C

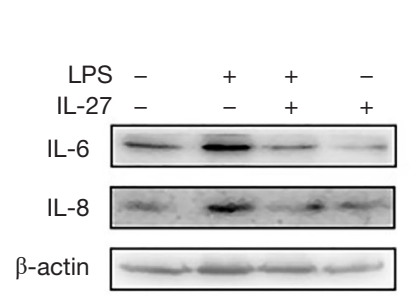

B
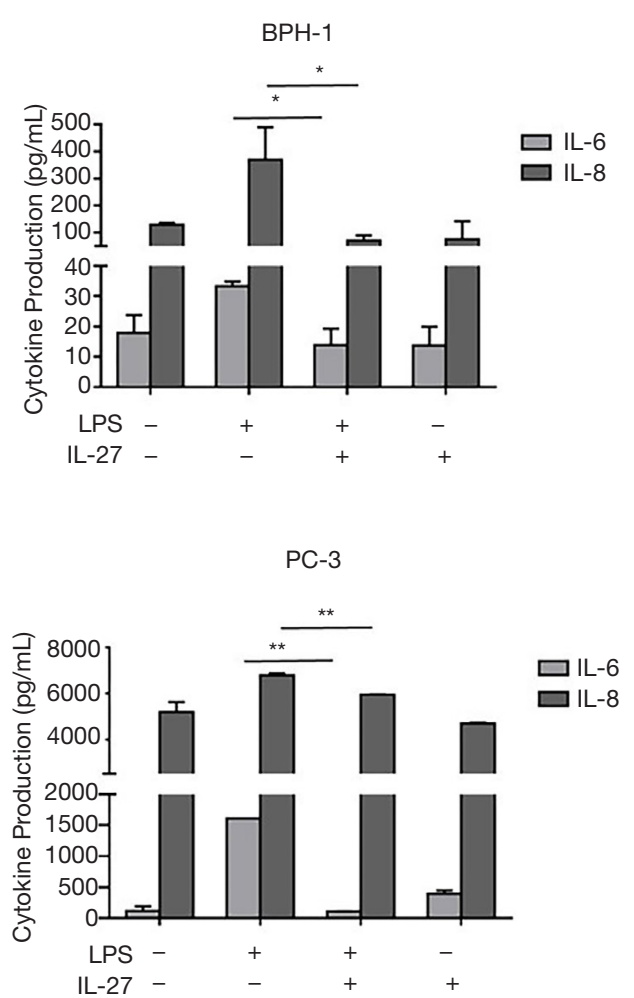

Figure 4 Suppression of Lipopolysaccharide (LPS)-induced interleukin 6 (IL-6) and IL-8 expression by IL-27/IL-27 receptor, $\alpha$ subunit (IL-27RA) signaling in BPH-1 and PC-3 cells. BPH-1 and PC-3 cells were treated with culture medium, LPS (10 $\mu \mathrm{g} / \mathrm{mL}), \mathrm{LPS}(10 \mu \mathrm{g} / \mathrm{mL})$ plus IL-27 $(50 \mathrm{ng} / \mathrm{mL})$, and IL-27 $(50 \mathrm{ng} / \mathrm{mL})$ for $6 \mathrm{~h}$. Then the cellular proteins and cell-free supernatants were collected and evaluated by western blotting and ELISA analysis. The relative expression of IL-6 and IL-8 in BPH-1 cells after treatment with LPS and/or IL-27 was determined by western blotting (A) and enzyme-linked immunosorbent assay (ELISA) analysis (B). The western blotting showed the expression of IL-8 was absent in BPH-1 cells. The relative expression of IL-6 and IL-8 in PC-3 cells after treatment with LPS and/or IL27 was measured by western blotting (C) and ELISA analysis (D). IL-6 and IL-8 expression in the group treated with LPS plus IL-27 was compared with group treated with LPS only. Semi-quantitation of western blotting was done by densitometry using ImageJ software. Data was representative of more than three independent experiments, with each performed in triplicate. ${ }^{*} \mathrm{P}<0.05,{ }^{* *} \mathrm{P}<0.001$

with smaller ones. This association of CI with higher serum PSA levels, larger prostate volumes, and bothersome LUTS requiring treatment by TURP in Taiwanese BPH patients supports the hypothesis that CI could lead to progression of $\mathrm{BPH}$.

Although clinical evidence supports CI as a key factor leading to $\mathrm{BPH}$, the underlying mechanism leading to differential prostate growth in widely distributed chronic inflammatory microenvironment is still unclear. Our comparative analysis of the gene expression profiles in $\mathrm{BPH}$ specimens from prostates of different size adds to a body of research that confirms the relationship between prostate size and activation of inflammatory genetic networks (3436). Together, these studies provide genetic evidence that inflammation/immune pathways might be involved in development and progression of $\mathrm{BPH}$ and $\mathrm{PCa}$.

Consistent with genetic evidence, Kramer and colleagues demonstrated that $\mathrm{BPH}$ tissue contains infiltrates of $\mathrm{T}$ cells, B cells, and macrophages that are chronically activated and responsible for the release of cytokines (mostly IL-2, interferon- $\gamma$, and TGF $\beta 1$ ) that may support fibromuscular growth in BPH (37). Among these immune cells Th17 cells that provide defense against extracellular pathogens through release of IL-17 other cytokines (38). Notably, the levels of IL-17 are negligible in normal prostate but highly increased in $\mathrm{BPH}$ tissues (5). IL-17, which activates the NF- $\mathrm{BB}$ pathway, regulates the expression of IL-6, IL- 8 , and IL- 1 in epithelial, endothelial, and stromal cells $(13,16,39,40)$; thus, IL-17 is considered a key cytokine in BPH development and progression. These previous studies, together with our 
A

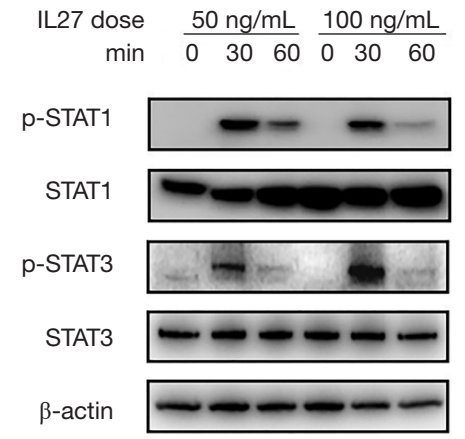

B
$\mathrm{BPH}-1$

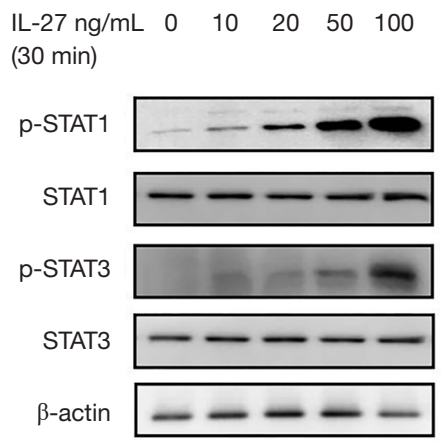

PC-3

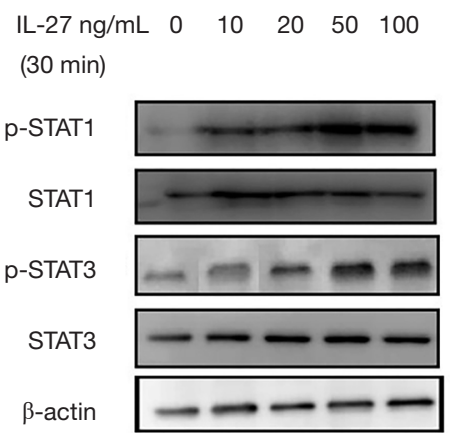

Figure 5 Phosphorylation of signal transducer and activator of transcription 1 (STAT1) and signal transducer and activator of transcription 3 (STAT3), the downstream effectors of IL-27/IL-27RA signaling, in BPH-1 and PC-3 cells after IL-27 stimulation. (A) The levels of phosphorylated STAT1 (p-STAT1) and phosphorylated STAT3 (p-STAT3) and total STAT1/STAT3 in BPH-1 cells were determined by western blotting at different time points $(0,30$, and $60 \mathrm{~min})$ and stimulated with different concentrations of IL-27 (0, 10, 20, 50, and 100 $\mathrm{ng} / \mathrm{mL}$ ). (B) The levels of p-STAT1/p-STAT3 and total STAT1/STAT3 in PC-3 cells were examined by western blotting with the same conditions as the BPH-1 cells. Data was representative of more than three independent experiments, with each performed in triplicate.

findings on the response to LPS via the TLR4 pathway, suggest a model in which prostate epithelial cells act as both sensors of infection and inducers of immune/inflammatory responses by expressing cytokines. These cytokines attract additional immune cells to augment inflammatory processes by expressing more potent cytokines, which stimulates epithelial cells in a vicious cycle (Figure 6A). These complex activities and interactions contribute to a chronic state of inflammation in BPH.

Interestingly, the expression of IL-17 signalingassociated genes was not significantly changed in our microarray data, suggesting that other cytokines contribute to the progression of BPH. We found that IL-27/IL-27RA signaling could modulate the production of LPS/TLR4 pathway-induced proinflammatory cytokines IL-6 and IL-8. IL-27, a pleiotropic cytokine that regulates multiple aspects of innate and adaptive immunity, has been associated with several inflammatory disorders including psoriasis (41), eczematous skin lesions (42), and periapical lesions (43). IL-27 is also part of the immune response to incoming pathogens. Studies have shown that IL-27 is induced by stimulation of TLR ligands or infectious agents (44-46). Although IL-27 is primarily produced by activated antigen presenting cells including dendritic cells and macrophages, 
A

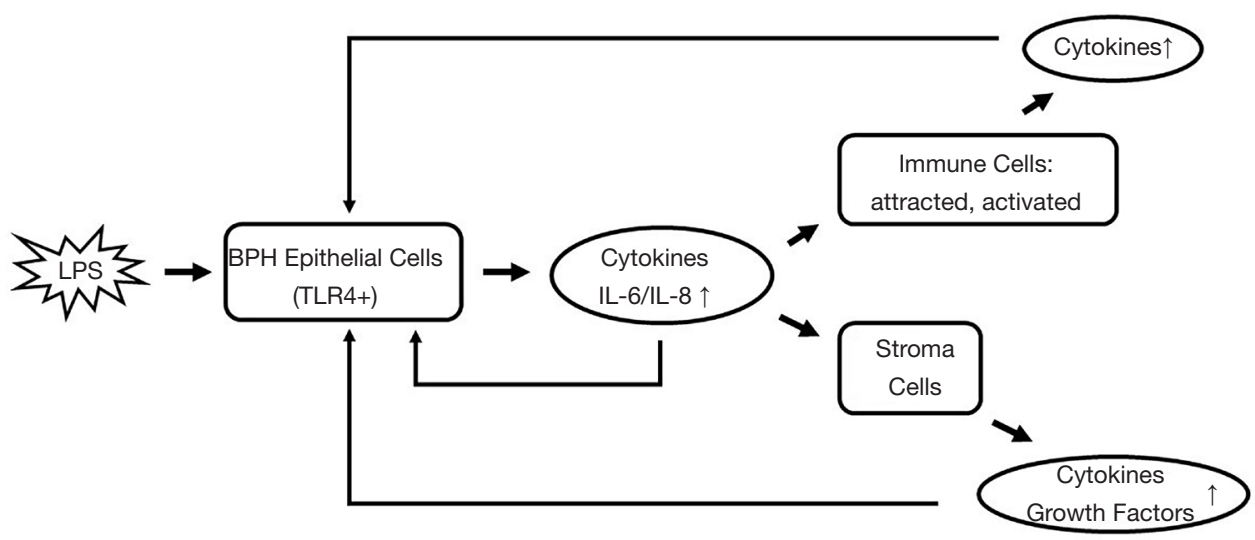

B

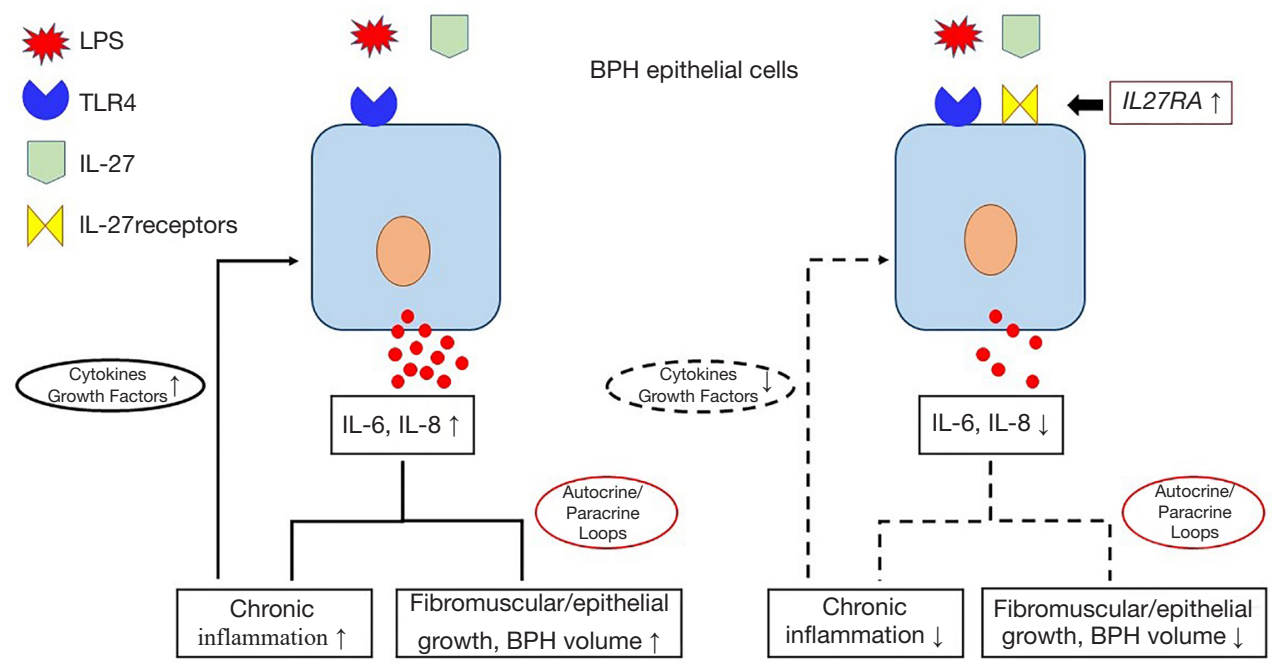

Figure 6 Schematic diagrams illustrating the complex activities and interactions contributing to a chronic state of inflammation in benign prostatic hyperplasia (BPH), and interleukin-27 (IL-27)/IL-27 receptor, alpha subunit (IL-27RA) signaling in modulation of inflammatory responses in BPH-1 cells and chronic inflammation in BPH progression. (A) Exogenous factors, such as LPS, activate the TLR4 pathway in BPH epithelial cells and induce production of inflammatory cytokines, which stimulate prostatic stromal and immune cells, and develop complex activities and feedback interactions that contribute to a chronic state of inflammation in BPH. (B) Left: In epithelial cells of BPH with less or absent expression of IL-27RA, Lipopolysaccharide (LPS)-activated toll-like receptor 4 (TLR4) signaling pathways induce production of proinflammatory and proliferative cytokines, interleukin-6 (IL-6) and IL-8, which lead to increased chronic inflammation and progression of BPH. Right: In epithelial cells of BPH with more or prominent expression of IL-27RA, activated IL-27/IL-27RA signaling suppresses production of IL-6 and IL-8 induced by the LPS/TLR4 pathway and attenuates chronic inflammation and progression of BPH.

several studies have revealed the capability of non-immune cells to express IL-27 $(47,48)$. Additionally, the IL-27 receptor is found not only on innate or adaptive immune cells, but also on non-hematopoietic cells such as epithelial cells, fibroblasts, and keratinocytes (48). Furthermore, recent studies have shown that IL-27 has dual functions in proinflammatory and anti-inflammatory processes in adipocytes (49), oral epithelial cells (50), synovial cells (51), and intestinal epithelial cells (52). To our knowledge, the role of IL-27/IL-27RA signaling in CI of the prostate is previously unreported. Our results suggest a key role of IL27/IL-27RA signaling in a negative feedback loop, which 
could modulate infectious or inflammatory responses in prostate cells. Therefore, we speculate that inside BPH tissues, when the activated TLR4 pathway induced IL-6 and IL-8 production by prostate epithelial cells, the IL-27 was also expressed by antigen-presenting or epithelial cells. The differential expression of $I L-27 R A$ leads to different degrees of the activated IL-27/IL-27RA signaling, differentially suppressing the TLR4 pathway in prostate epithelial cells, and attenuating proinflammatory responses and immune activation in $\mathrm{BPH}$ tissues (Figure $6 \mathrm{~B}$ ) as well as in PCa.

In the present study, both in microarray and in cell biology experiments, our data revealed that IL-6 and IL-8 play major roles in the immune/inflammatory responses of prostate epithelial cells. IL-6 is a pleiotropic cytokine influencing antigen-specific immune responses and inflammatory reactions as well as hematopoiesis, bone metabolism, and neural development (53). At the beginning of acute inflammation (AI), IL-6 mediates the acute phase responses. When its activity as a proinflammatory cytokine persists, AI turns into CI that includes immune responses (54). The coexistence of IL-6 secretion and IL6R expression on BPH stromal and epithelial cells suggest a probably paracrine and autocrine epithelial cell growth regulatory loop (55). Similarly, IL-6 is also secreted by neoplastic prostate epithelial cells and can stimulate $\mathrm{PCa}$ growth and progression through autocrine cross-activation of androgen receptor (56) and insulin-like growth factor-I receptor (IGF-IR) signaling (57). On the other hand, IL-8 is a proinflammatory cytokine, often induced along with IL-6 in response to chemical and microbial stimuli and selected cytokines. IL-8 stimulates stromal and epithelial growth by directly promoting the proliferation of senescent epithelial cells (58) and the stromal acquisition of a myofibroblast-reactive phenotype (59), and by indirectly inducing fibroblast growth factor-2 (FGF-2) secretion (60). The importance of IL-8 in prostatic CI was demonstrated by its increased levels in seminal plasma (61) and expressed prostatic secretion (62) in chronic prostatitis/chronic pelvic pain syndrome and in BPH. Thus, IL-8 is a reliable marker of $\mathrm{BPH}$ with $\mathrm{CI}$, based on its positive correlation with IPSS and serum PSA. In addition, IL- 8 is thought to be an important factor in tumor metastasis and resistance to treatment (63). The circulating level of IL-8 is increased in advanced $\mathrm{PCa}$ at the stage of hormone refractory and androgen independent metastasis (64). Thus, the expression of IL-8 may have significant prognostic value for PCa growth and response to therapy $(65,66)$.

There are several limitations to this study. First, it is hard to ascertain the origins of infection/inflammation and sources of IL-27 in complex BPH tissues by only microarray studies, and thus we acknowledge that validation of the modulatory mechanism of IL-27/IL-27RA signaling would require more experiments and acquire more samples from a large population of $\mathrm{BPH}$ patients. Second, while the expression of IL-27RA is similar in RWPE-1 and BPH1 cells (Figure 2B), the immunobiological features of IL27 signaling in these two benign prostate epithelial cell lines might be indistinguishable. On the other hand, it is well known that prostatic inflammation is involved in the carcinogenesis and progression of $\mathrm{PCa}$ and might be a link between BPH and PCa $(11,14,67)$. Thus, we chose to compare the effects of IL-27/IL-27RA signaling on LPS/ TLR4 pathway-induced inflammatory responses in BPH1 cells with PC-3 cells. Third, differential expression of IL27RA in the glandular epithelium of $\mathrm{BPH}$ might suggest the different activated status of IL-27 signaling between individuals facing infection versus CI. To further explore the role of IL-27RA, knockdown or overexpression of IL27RA in the components of $\mathrm{BPH}$ tissue would be required in future work.

In conclusion, our study is the first report that IL27RA is a biomarker of $\mathrm{CI}$ and a predictor of progression in $\mathrm{BPH}$ tissues. The gene expression of IL27RA is downregulated in larger prostates and correlated with increased serum PSA and a higher prevalence of CI. In cell biology experiments, IL-27/IL-27RA signaling could modulate LPS/TLR4 pathway-induced proinflammatory responses by suppressing IL-6 and IL-8 production in prostate cells. These data enrich our knowledge of the role of $\mathrm{CI}$ in $\mathrm{BPH}$, and highlight a novel function of activated IL-27/IL-27RA signaling in $\mathrm{BPH}$ tissues. These results suggest a novel mechanism of IL-27-mediated innate immunity during prostate infection/inflammation, which might be promising for the prevention and/or treatment of $\mathrm{BPH}$.

\section{Acknowledgments}

We thank Dr. Chung-Jen Su and Dr. Chun-Te Lee for assistance with acquiring BPH specimens, and the technicians at the National Center of Excellence for Clinical Trials and Research for technical assistance. We specially thank Professor Simon W. Hayward (Vanderbilt University Medical Center, Nashville, TN, USA) for kindly providing $\mathrm{BPH}-1$ cell line.

Funding: This study was supported by grants of the TriService General Hospital, Songshan Branch [grant numbers: 
9705, 9805, 9904, 10002, and 10102], and the Center of Biotechnology, National Taiwan University, Taiwan [grant number GTZ300].

\section{Footnote}

Data Sharing Statement: Available at http://dx.doi. org/10.21037/tcr-20-1509

Peer Review File: Available at http://dx.doi.org/10.21037/tcr20-1509

Conflicts of Interest: All authors have completed the ICMJE uniform disclosure form (available at http://dx.doi. org/10.21037/tcr-20-1509). EYC serves as an unpaid Editorin-Chief of Translational Cancer Research. The other authors have no conflicts of interest to declare.

Ethical Statement: The authors are accountable for all aspects of the work in ensuring that questions related to the accuracy or integrity of any part of the work are appropriately investigated and resolved. The study was conducted in accordance with the Declaration of Helsinki (as revised in 2013). The study was approved by the Institutional Review Board of TSGH (TSGHIRB Approval Number: 096-05-177) and an informed consent was taken from all the patients.

Open Access Statement: This is an Open Access article distributed in accordance with the Creative Commons Attribution-NonCommercial-NoDerivs 4.0 International License (CC BY-NC-ND 4.0), which permits the noncommercial replication and distribution of the article with the strict proviso that no changes or edits are made and the original work is properly cited (including links to both the formal publication through the relevant DOI and the license). See: https://creativecommons.org/licenses/by-nc-nd/4.0/.

\section{References}

1. Egan KB. The Epidemiology of Benign Prostatic Hyperplasia Associated with Lower Urinary Tract Symptoms: Prevalence and Incident Rates. Urol Clin North Am 2016;43:289-97.

2. Lokeshwar SD, Harper BT, Webb E, et al. Epidemiology and treatment modalities for the management of benign prostatic hyperplasia. Transl Androl Urol 2019;8:529-39.

3. Lee KL, Peehl DM. Molecular and cellular pathogenesis of benign prostatic hyperplasia. J Urol 2004;172:1784-91.

4. Kramer G, Marberger M. Could inflammation be a key component in the progression of benign prostatic hyperplasia? Curr Opin Urol 2006;16:25-9.

5. Kramer G, Mitteregger D, Marberger M. Is benign prostatic hyperplasia $(\mathrm{BPH})$ an immune inflammatory disease? Eur Urol 2007;51:1202-16.

6. Gandaglia G, Briganti A, Gontero P, et al. The role of chronic prostatic inflammation in the pathogenesis and progression of benign prostatic hyperplasia (BPH). BJU Int 2013;112:432-41.

7. Robert G, Descazeaud A, Nicolaiew N, et al. Inflammation in benign prostatic hyperplasia: a 282 patients' immunohistochemical analysis. Prostate 2009;69:1774-80.

8. Nickel JC, Roehrborn CG, O'Leary MP, et al. The relationship between prostate inflammation and lower urinary tract symptoms: examination of baseline data from the REDUCE trial. Eur Urol 2008;54:1379-84.

9. Roehrborn CG, Kaplan SA, Noble WD, et al. The impact of acute or chronic inflammation in baseline biopsy on the risk of clinical progression of BPE: Results from the MTOPS study. J Urol 2005;173:Abstract 1277.

10. Alcaraz A, Hammerer P, Tubaro A, et al. Is there evidence of a relationship between benign prostatic hyperplasia and prostate cancer? Findings of a literature review. Eur Urol 2009;55:864-73.

11. De Nunzio C, Kramer G, Marberger M, et al. The controversial relationship between benign prostatic hyperplasia and prostate cancer: the role of inflammation. Eur Urol 2011;60:106-17.

12. Vignozzi L, Gacci M, Maggi M. Lower urinary tract symptoms, benign prostatic hyperplasia and metabolic syndrome. Nat Rev Urol 2016;13:108-19.

13. Fibbi B, Penna G, Morelli A, et al. Chronic inflammation in the pathogenesis of benign prostatic hyperplasia. Int $\mathrm{J}$ Androl 2010;33:475-88.

14. De Marzo AM, Platz EA, Sutcliffe S, et al. Inflammation in prostate carcinogenesis. Nat Rev Cancer 2007;7:256-69.

15. Bostanci Y, Kazzazi A, Momtahen S, et al. Correlation between benign prostatic hyperplasia and inflammation. Curr Opin Urol 2013;23:5-10.

16. König JE, Senge T, Allhoff EP, et al. Analysis of the inflammatory network in benign prostate hyperplasia and prostate cancer. Prostate 2004;58:121-9.

17. Gatti G, Rivero V, Motrich RD, et al. Prostate epithelial cells can act as early sensors of infection by up-regulating TLR4 expression and proinflammatory mediators upon LPS stimulation. J Leukoc Biol 2006;79:989-98. 
18. Pei Z, Li H, Guo Y, et al. Sodium selenite inhibits the expression of VEGF, TGFbeta(1) and IL-6 induced by LPS in human PC3 cells via TLR4-NF-(K)B signaling blockage. Int Immunopharmacol 2010;10:50-6.

19. Di Silverio F, Gentile V, De Matteis A, et al. Distribution of inflammation, pre-malignant lesions, incidental carcinoma in histologically confirmed benign prostatic hyperplasia: a retrospective analysis. Eur Urol 2003;43:164-75.

20. St Sauver JL, Jacobsen SJ. Inflammatory Mechanisms Associated with Prostatic Inflammation and Lower Urinary Tract Symptoms. Curr Prostate Rep 2008;6:67-73.

21. De Nunzio C, Presicce F, Tubaro A. Inflammatory mediators in the development and progression of benign prostatic hyperplasia. Nat Rev Urol 2016;13:613-26.

22. Pflanz S, Timans JC, Cheung J, et al. IL-27, a heterodimeric cytokine composed of EBI3 and p28 protein, induces proliferation of naive CD4(+) $\mathrm{T}$ cells. Immunity 2002;16:779-90.

23. Pflanz S, Hibbert L, Mattson J, et al. WSX-1 and glycoprotein 130 constitute a signal-transducing receptor for IL-27. J Immunol 2004;172:2225-31.

24. Owaki T, Asakawa M, Morishima N, et al. A role for IL27 in early regulation of Th1 differentiation. J Immunol 2005;175:2191-200.

25. Yoshimoto T, Yoshimoto T, Yasuda K, et al. IL-27 suppresses Th2 cell development and Th2 cytokines production from polarized Th2 cells: a novel therapeutic way for Th2-mediated allergic inflammation. J Immunol 2007;179:4415-23.

26. Diveu C, McGeachy MJ, Boniface K, et al. IL-27 blocks RORc expression to inhibit lineage commitment of Th17 cells. J Immunol 2009;182:5748-56.

27. Batten M, Li J, Yi S, et al. Interleukin 27 limits autoimmune encephalomyelitis by suppressing the development of interleukin 17-producing T cells. Nat Immunol 2006;7:929-36.

28. Hamano S, Himeno K, Miyazaki Y, et al. WSX-1 is required for resistance to Trypanosoma cruzi infection by regulation of proinflammatory cytokine production. Immunity 2003;19:657-67.

29. Zolochevska O, Diaz-Quinones AO, Ellis J, et al. Interleukin-27 expression modifies prostate cancer cell crosstalk with bone and immune cells in vitro. J Cell Physiol 2013;228:1127-36.

30. Di Carlo E, Sorrentino C, Zorzoli A, et al. The antitumor potential of Interleukin-27 in prostate cancer. Oncotarget 2014;5:10332-41.
31. Nguyen DP, Li J, Tewari AK. Inflammation and prostate cancer: the role of interleukin 6 (IL-6). BJU Int 2014;113:986-92.

32. Neveu B, Moreel X, Deschenes-Rompre MP, et al. IL-8 secretion in primary cultures of prostate cells is associated with prostate cancer aggressiveness. Res Rep Urol 2014;6:27-34.

33. Hibbert L, Pflanz S, De Waal Malefyt R, et al. IL-27 and IFN-alpha signal via Stat 1 and Stat 3 and induce T-Bet and IL-12Rbeta2 in naive T cells. J Interferon Cytokine Res 2003;23:513-22.

34. Cai C, Jiang FN, Liang YX, et al. Classical and alternative nuclear factor-kappaB pathways: a comparison among normal prostate, benign prostate hyperplasia and prostate cancer. Pathol Oncol Res 2011;17:873-8.

35. Endo T, Uzawa K, Suzuki H, et al. Characteristic gene expression profiles of benign prostatic hypertrophy and prostate cancer. Int J Oncol 2009;35:499-509.

36. Descazeaud A, Rubin MA, Hofer M, et al. BPH gene expression profile associated to prostate gland volume. Diagn Mol Pathol 2008;17:207-13.

37. Kramer G, Steiner GE, Handisurya A, et al. Increased expression of lymphocyte-derived cytokines in benign hyperplastic prostate tissue, identification of the producing cell types, and effect of differentially expressed cytokines on stromal cell proliferation. Prostate 2002;52:43-58.

38. Rautajoki KJ, Kylaniemi MK, Raghav SK, et al. An insight into molecular mechanisms of human $\mathrm{T}$ helper cell differentiation. Ann Med 2008;40:322-35.

39. McKenzie BS, Kastelein RA, Cua DJ. Understanding the IL-23-IL-17 immune pathway. Trends Immunol 2006;27:17-23.

40. Steiner GE, Newman ME, Paikl D, et al. Expression and function of pro-inflammatory interleukin IL-17 and IL17 receptor in normal, benign hyperplastic, and malignant prostate. The Prostate 2003;56:171-82.

41. Shibata S, Tada Y, Kanda N, et al. Possible roles of IL27 in the pathogenesis of psoriasis. J Investig Dermatol 2010;130:1034-9.

42. Wittmann M, Zeitvogel J, Wang D, et al. IL-27 is expressed in chronic human eczematous skin lesions and stimulates human keratinocytes. J Allergy Clin Immunol 2009;124:81-9.

43. Li J, Wang R, Huang SG. Immunomodulatory activity of interleukin-27 in human chronic periapical diseases. Am J Transl Res 2017;9:1460-70.

44. Molle C, Nguyen M, Flamand V, et al. IL-27 synthesis induced by TLR ligation critically depends on IFN 
regulatory factor 3. J Immunol 2007;178:7607-15.

45. de Groot R, van Beelen AJ, Bakdash G, et al. Viral dsRNA-activated human dendritic cells produce IL-27, which selectively promotes cytotoxicity in naive CD8+ T cells. J Leukocyte Biol 2012;92:605-10.

46. Yoshida H, Hunter CA. The immunobiology of interleukin-27. Annu Rev Immunol 2015;33:417-43.

47. Larousserie F, Bsiri L, Dumaine V, et al. Frontline Science: Human bone cells as a source of IL-27 under inflammatory conditions: role of TLRs and cytokines. J Leukocyte Biol 2017;101:1289-300.

48. Hall AO, Silver JS, Hunter CA. The Immunobiology of IL-27. Adv Immunol 2012;115:1-44.

49. Nam H, Ferguson BS, Stephens JM, et al. Modulation of IL-27 in adipocytes during inflammatory stress. Obesity (Silver Spring) 2016;24:157-66.

50. Hosokawa Y, Hosokawa I, Ozaki K, et al. IL-27 Modulates Chemokine Production in TNF-alpha -Stimulated Human Oral Epithelial Cells. Cell Physiol Biochem 2017;43:1198-206.

51. Niedbala W, Cai B, Wei X, et al. Interleukin 27 attenuates collagen-induced arthritis. Ann Rheum Dis 2008;67:1474-9.

52. Wang L, Cao J, Li C, et al. IL-27/IL-27 Receptor Signaling Provides Protection in Clostridium difficileInduced Colitis. J Infect Dis 2018;217:198-207.

53. Steiner GE, Djavan B, Kramer G, et al. The picture of the prostatic lymphokine network is becoming increasingly complex. Rev Urol 2002;4:171-7.

54. Gabay C. Interleukin-6 and chronic inflammation. Arthritis Res Ther 2006;8 Suppl 2:S3.

55. Hobisch A, Rogatsch H, Hittmair A, et al. Immunohistochemical localization of interleukin-6 and its receptor in benign, premalignant and malignant prostate tissue. J Pathol 2000;191:239-44.

56. Malinowska K, Neuwirt H, Cavarretta IT, et al. Interleukin-6 stimulation of growth of prostate cancer in vitro and in vivo through activation of the androgen receptor. Endocr Relat Cancer 2009;16:155-69.

57. Rojas A, Liu G, Coleman I, et al. IL-6 promotes prostate tumorigenesis and progression through autocrine cross- activation of IGF-IR. Oncogene 2011;30:2345-55.

58. Castro P, Xia C, Gomez L, et al. Interleukin-8 expression is increased in senescent prostatic epithelial cells and promotes the development of benign prostatic hyperplasia. Prostate 2004;60:153-9.

59. Schauer IG, Ressler SJ, Tuxhorn JA, et al. Elevated epithelial expression of interleukin- 8 correlates with myofibroblast reactive stroma in benign prostatic hyperplasia. Urology 2008;72:205-13.

60. Giri D, Ittmann M. Interleukin-8 is a paracrine inducer of fibroblast growth factor 2, a stromal and epithelial growth factor in benign prostatic hyperplasia. Am J Pathol 2001;159:139-47.

61. Penna G, Mondaini N, Amuchastegui S, et al. Seminal plasma cytokines and chemokines in prostate inflammation: interleukin 8 as a predictive biomarker in chronic prostatitis/chronic pelvic pain syndrome and benign prostatic hyperplasia. Eur Urol 2007;51:524-33; discussion 533.

62. Liu L, Li Q, Han P, et al. Evaluation of interleukin-8 in expressed prostatic secretion as a reliable biomarker of inflammation in benign prostatic hyperplasia. Urology 2009;74:340-4.

63. Waugh DJ, Wilson C. The interleukin-8 pathway in cancer. Clin Cancer Res 2008;14:6735-41.

64. Araki S, Omori Y, Lyn D, et al. Interleukin-8 is a molecular determinant of androgen independence and progression in prostate cancer. Cancer Res 2007;67:6854-62.

65. Singh RK, Lokeshwar BL. Depletion of intrinsic expression of Interleukin-8 in prostate cancer cells causes cell cycle arrest, spontaneous apoptosis and increases the efficacy of chemotherapeutic drugs. Mol Cancer 2009;8:57.

66. Xu Y, Fang F, St Clair DK, et al. Inverse relationship between PSA and IL-8 in prostate cancer: an insight into a NF-kappaB-mediated mechanism. PLoS One 2012;7:e32905.

67. Orsted DD, Bojesen SE. The link between benign prostatic hyperplasia and prostate cancer. Nat Rev Urol 2013;10:49-54.
Cite this article as: Lo HC, Yu DS, Gao HW, Tsai MH, Chuang EY. IL-27/IL-27RA signaling may modulate inflammation and progression of benign prostatic hyperplasia via suppressing the LPS/TLR4 pathway. Transl Cancer Res 2020;9(8):4618-4634. doi: 10.21037/tcr-20-1509 
Table S1 Genetic networks of genes differentially expressed between large and small prostate glands

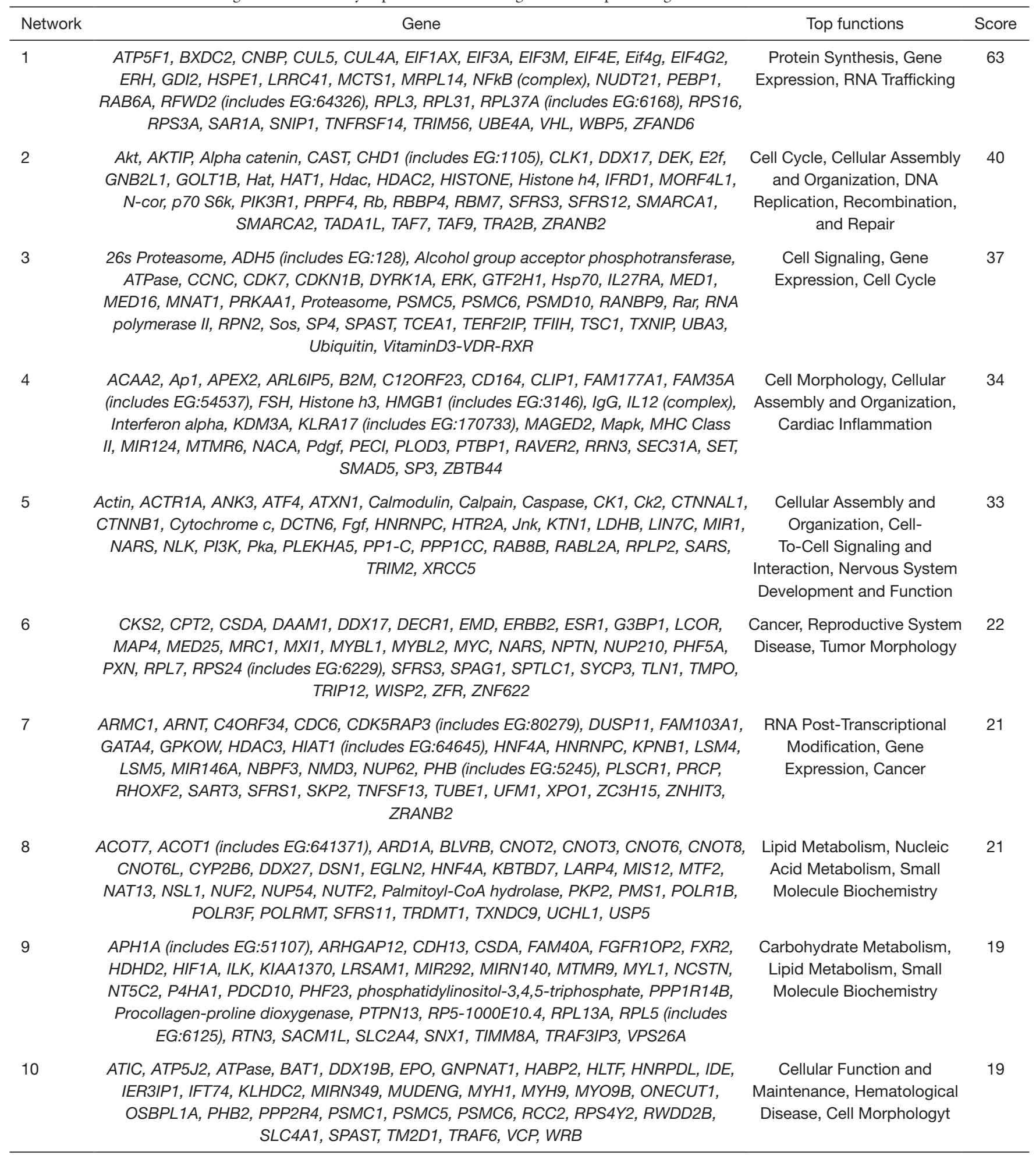


Table S2 Canonical pathways of genes differentially expressed between large and small prostate glands

\begin{tabular}{llc}
\hline Canonical pathway & $-\log (\mathrm{P}$ value $)$ & Associated gene number \\
\hline TREM1 Signaling & $6.58+\mathrm{E} 00$ & 13 \\
LXR/RXR Activation & $6.29+\mathrm{E} 00$ & 19 \\
Communication between Innate and Adaptive Immune Cells & $6.16+\mathrm{E} 00$ & 14 \\
IL-10 Signaling & $5.53+\mathrm{E} 00$ & 13 \\
Production of Nitric Oxide and Reactive Oxygen Species in & $5.49+\mathrm{E} 00$ & 22 \\
Macrophages & & 21 \\
Acute Phase Response Signaling & $5.48+\mathrm{E} 00$ & 18 \\
Hepatic Fibrosis/Hepatic Stellate Cell Activation & $4.91+\mathrm{E} 00$ & 28 \\
Role of Macrophages, Fibroblasts and Endothelial Cells in & $4.79+\mathrm{E} 00$ & \\
Rheumatoid Arthritis & & 12 \\
Interferon Signaling & $4.45+\mathrm{E} 00$ & $4.27+\mathrm{E} 00$ \\
Altered T Cell and B Cell Signaling in Rheumatoid Arthritis & & \\
\hline
\end{tabular}

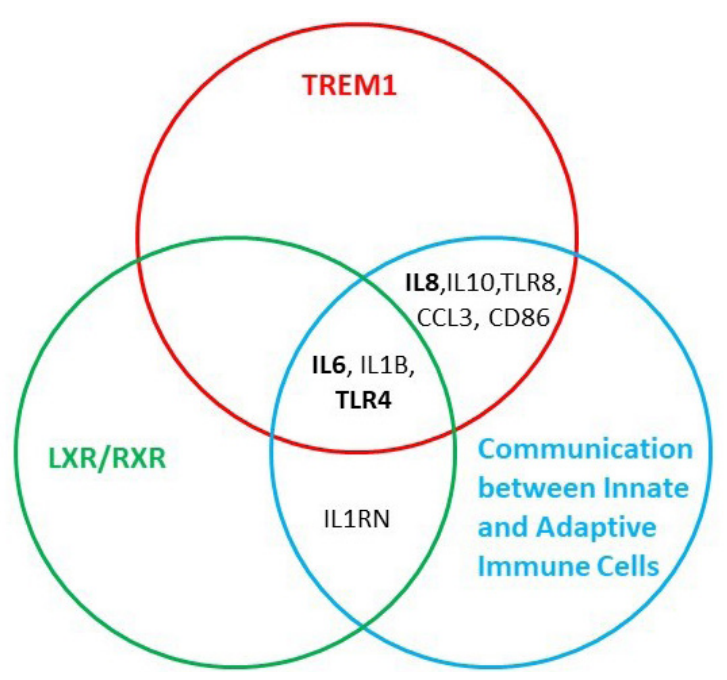

Figure S1 The genes among the top 3 canonical pathways whose expression simultaneously changed. Differentially expressed genes that were common among top 3 pathways were selected to design cellular experiments to validate the role of IL-27RA in mediating immunerelated inflammation and effecting growth of prostate glands. 